\title{
Participation, Deliberation, and We-thinking
}

Philip Pettit

One of the most influential arguments for the value of political participation is Carole Pateman's early book Participation and Democratic Theory (Pateman 1970). In this essay I explore the ideal with which she was concerned, identify a problem for its implementation, and then describe a strategy under which the problem can be overcome. The strategy makes a connection between the participatory ideal of democracy and what has come to be known as the deliberative ideal of democracy; specifically, it connects with the sort of deliberation that involves what I describe, for want of a better term, as we-thinking.

My focus will not be on democratic process in the large-scale context of an electorate; participatory democracy is very hard to achieve in that context. Following Pateman's lead, I will be exploring the prospects for participatory democratic processes in smaller scale contexts. Where she concentrated in particular on industrial democracy, however, I shall be concerned more generally with the possibility of democratizing a variety of decision-making units, ranging from workplaces to boardrooms, from civic associations to formal committees, from government departments to religious groupings.

In the first section of this paper I look at the content of the ideal of participatory democracy and, in the second, at the context of group behavior for which it is an ideal. In the third section I identify the problem that arises for the ideal; in the fourth section I show how a certain sort of decision-making process can solve this problem; and in the fifth and final section I comment on the deliberative we-thinking that this inevitably involves. Such we-thinking is not much discussed in the literature on deliberative democracy but assumes the first importance in any genuinely participatory theory. 


\section{The Content of the Participatory Ideal}

What does it mean to make a decision-making process participatory? At the least, it means that the process should give everyone a say, and ideally an equal say. This argues at a first level that whatever form the decision-making process takes over different issues, it ought to be one that has everyone's approval. It ought to be unanimously endorsed as a way to make decisions in the relevant context, local or global; it ought to be a process that could be vetoed by anyone but is actually vetoed by none.

This unanimitarian requirement might be extended from approval of the decision-making process itself to approval of each decision made. The requirement might be not just that the procedure for making decisions is one that all approve, but that it is a procedure under which everyone must approve of each decision made. By all accounts, however, this is not going to be a feasible arrangement. The circumstances of politics, even in relatively nonpluralistic environments, are such as to make disagreement inevitable (Waldron 1999). And that means that a decision-making group that is committed to unanimity is unlikely to be able to get its business done.

The absolutely standard line, in view of this consideration, is that the way forward for participatory democracy is to require unanimous approval for a non-unanimitarian mode of decision making: usually, for a majoritarian mode, or for a majoritarian mode that puts in certain protections against majority abuse. This line is already to be found in thinkers as different as Thomas Hobbes ([1651] 1994) and Jean Jacques Rousseau ([1750, 1755, 1762] 1973).

Hobbes's name is not naturally associated with the ideal of democracy, but there are at least two respects in which he displays democratic credentials. First of all, he insists that the establishment of a sovereign who can speak for the people should be unanimously accepted among the members. "A multitude of men are made one person, when they are by one man, or one person, represented so that it be done with the consent of every one of that multitude in particular" (Hobbes [1651] 1994, 104). And second, he allows that the sovereign might in principle consist of a committee, in particular a committeeof-the-whole, and that such a committee ought to make its decisions by majority voting. "And if the representative consist of many men, the voice of the greater number must be considered the voice of them all" (104).

If Hobbes is unusual, that is mainly because he puts few if any effective limits on the power of the sovereign, including the sovereign people. Rousseau argues, first, that the committee-of-the-whole is the only legitimate sovereign, 
not just one possible sovereign among many; and second, that as the sovereign it is limited to legislating for the people in accord with rule-of-law constraints and cannot take on executive or other governmental duties. He follows Hobbes, however, in thinking that everyone in a society ought to approve of establishing the assembled people as this sort of legislative sovereign and that that assembled body ought to make its decisions by majority vote. He writes: "one law . . . needs unanimous consent . . . the social compact. . . . Apart from this primitive contract, the vote of the majority always binds all the rest" (Rousseau [1750, 1755, 1762] 1973, bk. 4, chap. 2).

The Hobbes-Rousseau template for participatory democracy might be applied, not just to the society as a whole, but to any decision-making site. Generalized in this way, it involves two steps. First, members are to endorse unanimously the decision-making procedure proposed for the site. And, second, that procedure is to give pride of place to majority voting, even if it is constrained to protect individual members against what would count, by unanimous agreement, as majority abuse. We may take the need for constraint as granted and describe the ideal, in a phrase, as unanimously accepted majority rule. There are different things that majority rule can mean, but I ignore that ambiguity here; as things turn out, it won't matter for our purposes.

If this model of participatory democracy is to have any chance of commanding allegiance, at least two stipulations should be explicitly added; they normally go without saying, and will do so in the remainder of this paper. The first is that those who make the decisions at any site should include everyone who lives or operates there as a member; what it means to live or operate at a site, of course, will vary between different cases. And the second is that those decision makers at any time should not be irreversibly constrained by the decisions of previous generations.

At each time, then, the voting members should include all the members there are. And at each time the members should be able to reconsider and, if this is thought sensible, reverse the decisions of the past membership. The first provision guards against synchronic control of some members by others, the second against diachronic control of the members at one time by the members at earlier times. This second provision need not mean that every decision should be regularly renewed, as in Jefferson's idea of having each generation make its own constitution (Rubenfeld 2001, 18-19). Rousseau ([1750, 1755, 1762] 1973, bk. 3, chap. 9) takes a more sensible line. "Yesterday's law is not binding today; but silence is taken for tacit consent, and the 
Sovereign is held to confirm incessantly the laws it does not abrogate as it might."

\section{The Context in Which the Ideal Applies}

What sort of enterprise is meant to be governed by the ideal of participatory democracy? There are two starkly contrasting answers in the literature. According to one account, the enterprise is that of determining for a range of choices the option that answers best in each case to the preexisting preferences of the parties in the group. According to the other, the enterprise is that of determining how best some goals can be advanced by the members of the group or by their representatives.

Under the first account, participatory democracy is cast as a method for aggregating the preference orderings of members, now on the options in this choice, now on the options in that. Under the second account, it is taken as a method for aggregating the judgments of the members on issues to do with the specification, ordering, and urgency of the goals; on the opportunities available for pursuit of those goals and the problems arising from tensions between their demands; and on the best means to adopt, or the best agents to recruit, in advancing the goals. Under the first account, the group is cast as a passive beneficiary of whatever choices will be made, and the aim is to make sure that the benefit maximizes preference satisfaction overall; the idea is that that aim will be best advanced by polling members on what they each most want. Under the second account, the group is cast as an active choice-making agency, and the aim is to get members to form a common mind on the judgments required; the idea is that members can best do this by pooling their views on the matters the group has to address.

Given that participatory democracy is taken here as a method that can be used at many sites, not just in an electoral context, we have to conceive of it as a way for members of the relevant group to pool their views, not just as a way of polling them for their preferences. Think of those on the shop floor who participate, as under Pateman's model of industrial democracy, in determining the priorities of the firm. Think of those in a department of state who participate in deciding on how to implement a set of policy goals. Or think of the members of a voluntary association who participate in organizing the annual activities of the group. In none of these cases can participatory democracy be cast as a means for maximizing preference satisfaction. Its primary function will be to ensure that the requisite pattern of decision making will 
be implemented in a way that gives each member a say, ideally an equal say, in forming the judgments that guide decision.

There is a sense, of course, in which any pattern of choices on which the members converge in such a case will show what in some sense they most prefer. But this should not distract us from the distinctive character of the exercise. If as an individual agent one adopts a means for advancing some goal on the grounds that it is the most efficient way of doing so, then there is a sense in which this will show what one most wants. But whatever the choice shows about what one most wants, the grounds for making it will not be that it produces the most satisfaction of want; one will not have decided upon it under that aspect. There will still be an intuitive contrast between the case envisaged, then, and a case where one does look as such for the way to best satisfy certain antecedent wants (Pettit 2006). A similar contrast obtains between the exercise in which people try to come to a common mind on how best to specify or promote certain goals and the exercise in which they try to determine which of various options answers best to their antecedent desires. If they form the judgment that such and such an option is the thing to do, and then enact it, we can say that that was the action that appealed to them most, or that they wanted most. But the appeal of the action will have been that it was the best means to their ends, not that it answered best to their antecedent desires.

One way of emphasizing the contrast between the two sorts of cases mentioned has a particular prominence in the discussion of deliberative democracy (Sunstein 1993). This is to point out that while there is a sense in which preference satisfaction may be achieved under both procedures, the relationship between the preferences and the procedure is quite different in each case. In one, the preferences are brought to the table and the question raised is how best to satisfy them. In the other, the question of what judgments to form is brought to the table and preferences materialize in the course of resolving that issue. The preferences are the input to the procedure in the first case and the output of the procedure in the second.

In view of the various sites at which it is supposed to apply, I shall assume that participatory democracy is meant to be an ideal for the second sort of case, not the first. It is an ideal for how the members of a decision-making group should pool their judgments, not an ideal for how members should be polled on antecedent preferences. This makes good independent sense anyhow, as it sharpens the contrast between participatory, policy-making democracy and the indirect, electoral form of democracy in which personnel are selected to make policies elsewhere. 


\section{A Problem for the Ideal}

When democracy is cast as a matter of aggregating preference orderings, then notoriously, it runs into conflict with Kenneth Arrow's famous impossibility theorem (Arrow 1963). This shows that there is no satisfactory voting procedure that can guarantee it will produce a rational preference ordering over the options in a group choice, on the basis of the rational preference orderings of members. Take transitivity of preference, which consists in the fact that if $\mathrm{A}$ is preferred to $\mathrm{B}$, and $\mathrm{B}$ to $\mathrm{C}$, then $\mathrm{A}$ is preferred to $\mathrm{C}$. Arrow shows that transitive input orderings are liable to generate an intransitive group ordering, if the voting procedure has to satisfy certain intuitively attractive constraints: if it has to work for all inputs, treat no one as a dictator, select any option that is universally preferred to alternatives, and remain constant even as irrelevant alternatives are introduced.

Do we escape this sort of aggregation problem in insisting that participatory democracy is not about the aggregation of preference orderings but about group decision making? I want to argue that even if we do escape this and related problems (Coleman and Ferejohn 1986), we have to face a distinct issue of aggregation, indeed an issue that is arguably more general in character (List and Pettit 2004). This is a problem, not in the aggregation of preference, but in the aggregation of judgment. It does not focus on the difficulty in putting together our individual orderings of the options in a given choice. Rather, it turns on the difficulty of putting together the different sets of judgments that we will each have to form in the course of considering a series of choices that we face as a group.

Take any range of choices that we may confront as a group, whether at the same time or over a stretch of time. Selecting an option in any one choice will require a number of judgments. In each case there will be a question as to the various options available as alternatives, the relevance and urgency of different goals, the extent to which those goals can be simultaneously serviced by different options, and the relative merits of the different options as means of realizing the goals; and this latter issue will usually ramify into a variety of subordinate issues about causal connections, likely consequences of the different options, and so on. Assuming that we are each to have a say on what the group decides in any such choice, and in the range of choices overall, we will each need to form a personal judgment on every question raised, and so we will each have to develop quite a complex body of judgments.

The bodies of judgment we form will inevitably be quite different, however, even if we consult one another in the course of forming them; the burdens of 
judgment, as John Rawls (1993) calls them, will ensure that we go different ways. And so there will be a problem as to how our different bodies of judgment are to be aggregated into a single body of judgment: one that the group can act on when it acts as a whole-if it ever does this-and one that those authorized to speak or act in its name can be required to follow.

It may seem that we can wheel in the participatory ideal of unanimously endorsed majority voting to solve this problem of aggregation. After all, the obvious thing to do in determining the group view on any issue, say whether or not it is the case that $\mathrm{p}$, is to take a vote among the members and to let the group view be determined by the majority view among the membership. But this, it turns out, we cannot do-at least not with any assurance that the group will be able to perform as a rational decision-making center.

The problem is one that I have described elsewhere as the discursive dilemma (Pettit 2001, chap. 5; 2003c). Assume that if a group is to be able to perform as a decision-making center, then it must be able to ensure consistency in its judgments; it must be sensitive to the recognition of inconsistencies, even if it occasionally slips on this front. This is a reasonable assumption since the group that is insensitive to the inconsistency of its judgments on issues related to action will be unable to make a rational decision on what to do. The problem that arises with the majoritarian aggregation of judgments on a range of issues, in particular a range of issues that are logically connected with one another, is that individuals with perfectly consistent sets of judgments on those issues can vote for a set of group judgments that is quite inconsistent.

Let me illustrate the problem schematically, to begin with. Consider a group of three agents, A, B, and C. Imagine that under the pressure of decision and action, they have to form judgments, now on whether $\mathrm{p}$, now on whether $\mathrm{q}$, now on whether $\mathrm{r}$, and yet again on whether p\&q\&r. All but A might vote for $\mathrm{p}$; all but B for q; all but $\mathrm{C}$ for $\mathrm{r}$; and, consequently, none for $\mathrm{p} \& \mathrm{q} \& \mathrm{r}$ : each would reject it because of rejecting one conjunct. These votes would have the group holding that $\mathrm{p}$, that $\mathrm{q}$, that $\mathrm{r}$, but that not-p\&q\&r. The position would be as represented in the following matrix:

\begin{tabular}{llllc} 
& $p ?$ & $q ?$ & $r ?$ & $p \xi q \xi r ?$ \\
\hline A & No & Yes & Yes & No \\
B & Yes & No & Yes & No \\
C & Yes & yes & No & No \\
Majority & Yes & Yes & Yes & No \\
\hline
\end{tabular}


This problem can be readily illustrated with real-life examples. Consider an issue that might arise in a workplace, among the employees of a company: say, for simplicity, a company owned by the employees (Pettit 2001, chap. 5). The issue is whether to forego a pay rise in order to spend the money thereby saved on introducing a workplace safety measure: perhaps a guard against electrocution. Let us suppose for convenience that the employees are to make the decision-perhaps because of prior resolution-on the basis of considering three separable issues: first, whether there is a serious danger of electrocution, by some agreed benchmark; second, whether the safety measure that a pay sacrifice would buy is likely to be effective, by an agreed benchmark; and third, whether the pay sacrifice involves an intuitively bearable loss for individual members. If an employee thinks that the danger is sufficiently serious, the safety measure sufficiently effective, and the pay sacrifice sufficiently bearable, he or she will vote for the sacrifice; otherwise they will vote against. And so each will have to consider the three issues and then look to what should be concluded about the pay sacrifice.

The pattern here is exactly as in the case with $\mathrm{p}, \mathrm{q}, \mathrm{r}$, and p\&q\&r. And as in that case, the employees may have views such that if the majority view on each issue is to fix the group view, then the group will end up with an inconsistent set of views. Let $\mathrm{A}, \mathrm{B}$, and $\mathrm{C}$ represent the employees; if there are more than three employees, the problem can still arise. A, B, and C may hold the views ascribed in the following matrix, generating the inconsistent majority set of views represented in the bottom row.

\begin{tabular}{lcccc} 
& $\begin{array}{c}\text { Serious } \\
\text { danger? }\end{array}$ & $\begin{array}{c}\text { Effective } \\
\text { measure? }\end{array}$ & $\begin{array}{c}\text { Bearable } \\
\text { loss? }\end{array}$ & $\begin{array}{c}\text { Pay } \\
\text { sacrifice? }\end{array}$ \\
\hline A. & No & Yes & Yes & No \\
B. & Yes & No & Yes & No \\
C. & Yes & Yes & No & No \\
Majority & Yes & Yes & Yes & No \\
\hline
\end{tabular}

It may seem that the participatory ideal might be altered, so that what is required is not a procedure of majority voting but a procedure of some other kind. But this avenue does not hold out much promise. The problem is that, even with wholly consistent individual voters, no voting procedure can be guaranteed to generate a consistent set of judgments on a logically connected set of issues if it is to satisfy three conditions. These are, first, that it work under any variation in the input bodies of judgment; second, that it treat 
every individual as an equal in the voting procedure, giving no one a casting vote and allowing no one a dictatorial position; and, third, that it treat every issue in its own right as an issue to be determined by the members' views on that question, not by what their views on other issues imply. We may refer to those conditions as universal domain, voter anonymity, and voting systematicity. There is now a formal theorem to the effect that no procedure satisfying those conditions can guard against the sort of inconsistency illustrated by the discursive dilemma (List and Pettit 2002; for references to later theorems see List and Pettit 2005). This theorem shows that it is impossible for a voting procedure to guarantee to deliver a complete, consistent set of judgments as the output from complete, consistent input sets, and at the same time conform to universal domain, voter anonymity, and voting systematicity.

This impossibility is threatening-perhaps more threatening than the Arrovian impossibility-so far as it hangs over any group, as the group continues to make decisions through time and builds up a record of judgments. For as the group commits itself to more and more propositions, say by majority voting, the probability increases that it will have to make up its mind on a proposition such that existing commitments imply that it should be resolved in one way (as commitments on $\mathrm{p}$, $\mathrm{q}$, and $\mathrm{r}$ imply that the group should endorse $\mathrm{p} \& \mathrm{q} \& \mathrm{r}$ ) but the majority vote goes in the opposite direction. This would not be a problem if the group could just ignore past judgments, treating them like the judgments of a different subject. But of course the normal, democratically organized body won't be able to do this. It will be subject to expectations of diachronic as well as synchronic consistency, both by its own members and by other groups and individuals. Unless it sustains such expectations it won't be able to display the scrutable profile of an agent; it won't be able to commit itself to others in promises, contracts, and the like; and it won't be capable of being subjected to a discipline of non-arbitrary decision making: for those over whom it exercises authority it will have the aspect of a wayward force in their lives.

Solving the Problem

The problem posed by the impossibility theorem is not insurmountable, however. What the theorem shows, in effect, is that there may be ways in which a group can form judgments that are reliably consistent, but they must breach one or another of the presuppositions of the theorem. The group might avoid the problem raised, for example, by renouncing the ideal of forming complete judgments over all the issues it faces. It might decide to suspend judgment on 
one of any set of issues where majority voting would lead it into inconsistency. This, however, won't be a very satisfactory way of dealing with the difficulty. The group will only be disposed to form judgments on issues related to the choices or decisions it has to make, and any suspension of judgment is liable to constrain its capacity for decision and action. A more promising line would be for the group to avoid the problem raised, by taking steps that reduce its commitment to universal domain, voter anonymity, or voting systematicity.

The group might try to reduce its commitment to universal domain by imposing a discipline of deliberation designed to push individuals toward an unproblematic configuration of views: a configuration that is unlikely to generate inconsistency on the basis of majority voting (List 2002). There is no guarantee, however, that such a discipline can be identified and reliably implemented. The more promising ways for a group to escape the problem would be to reduce its commitment to either voter anonymity or voting systematicity: either to the principle that every voter should be treated equally or to the principle that every issue should be treated on its own merits.

The way in which most groups manage to conduct the formation of judgment and the making of decisions is by breaching voter anonymity, giving some individuals a special role. A common but extreme form of this is represented by how the shareholders in a company invest the board with the power of making judgments in the company's name, when the exercise of this power can only be challenged with difficulty. The situation approximates the way in which, according to Hobbes, the people in a commonwealth invest the sovereign with a more or less unconstrained power of judgment and decision making. The alienation of such power may also take less extreme forms, of course. It might consist, for example, in an arrangement whereby the members of a group give one individual authority to decide the group's judgments, should inconsistencies arise from majority voting. The position of the courts in relation to a legislature can resemble that sort of regime, with the courts reinterpreting what the legislature declares in order to ensure that its dictates come out as consistent.

But while many groups maintain consistency in judgment by giving certain parties special privileges in this way, the strategy cannot represent a natural path for a group that is committed to participatory democracy, being disposed to decide everything by majority vote. To give over authority to an individual or subset of individuals, in however small a measure, is inevitably to diminish the ideal of participatory democracy. It is to reduce the participation that people enjoy in the decisions faced by the group.

This leaves only one strategy whereby a group might hope to ensure collec- 
tive consistency and yet remain true to the ideal of participatory democracy. The strategy would consist in reducing the commitment to systematicity, and allowing that on some issues the view of the group need not be decided by the members' views on that issue; it is to be decided, rather, by their views on related issues. Think about the schematic case where $\mathrm{A}, \mathrm{B}$, and $\mathrm{C}$ vote in such a way that the group is forced by majority voting to claim that $\mathrm{p}$, that $\mathrm{q}$, that $\mathrm{r}$, but that not-p\&q\&r. Were systematicity not enforced, then it would be possible to have the group's judgment on, say, p\&q\&r determined by member votes on $\mathrm{p}, \mathrm{q}$, and $\mathrm{r}$, rather than by member votes on the compound proposition itself; and it would be possible to ensure consistency thereby in the group's judgments as a whole. Indeed the same holds for each proposition. Absent the requirement of systematicity, it would be possible to have the group's judgment on any of the four propositions determined by member votes on the other three, thereby ensuring consistency. If the members vote "yes" for $\mathrm{p}$, for q, and for $\mathrm{p} \&$ $q \& r$, for example, then those votes will dictate a vote for not-q; and if systematicity is not enforced, then this will be permissible.

What form, more positively, might the rejection of systematicity take? It is one thing to say that inconsistency ceases to be inevitable if systematicity is not enforced. It is quite another to identify tactics for determining where systematicity should be breached and breached in a way that saves consistency. There are two families of approaches. One would enforce a static procedure, fixed in advance for all cases. The other would invoke a more dynamic, open-ended process.

Just to illustrate the static procedure, the group might decide to authorize past judgments over present judgments in the case of any inconsistency arising from majority voting, and to let past judgments trump the present judgment, regardless of the majority support it enjoys. Suppose that our group of workers had committed to the first three propositions in the matrix given, prior to considering the issue of the pay sacrifice. This strategy would deny them the possibility of reconsidering any of those past judgments in the light of where, as it turns out, they lead: to acceptance of the pay sacrifice. It would force the group to impose on itself procrustean, potentially irrational constraint. It would forbid any change of mind.

Still illustrating the static procedure, the group might decide to prioritize more general issues over more specific ones, rather than issues addressed previously over issues under current consideration. It might decide that its judgments on more general issues should determine its judgments on more specific ones, whenever systematicity would lead to inconsistency. But this again would be a costly approach to take. It would deny the group any possi- 
bility of following the method of reflective equilibrium described by John Rawls (1971), since such equilibration consists in going back and forth between more general and more specific judgments, seeking out the best place at which to make revisions and ensure coherence.

The basic problem with reducing the commitment to systematicity in any such static manner is that it will require a group to prioritize certain judgment types once for all time-more general judgments, for example, or judgments addressed earlier-and to let them dictate what other judgments should be endorsed. But this will often lead the group, intuitively, toward the wrong views. Propositions do not come prepackaged into the more privileged issues that ought to be decided first and the less privileged issues that ought to be decided by reference to the pattern of judgment in the privileged category. In reasoning sensibly about what to believe we are often led as individuals to revise past beliefs in the light of current inclinations (Harman 1986). It would be crazy to deny ourselves in groups an exercise of intelligence that we prize as individuals.

This takes us, finally, to the dynamic version of the strategy of rejecting systematicity. The best way of summing this up may be to describe a set of instructions whereby a group could be enabled to implement it. The instructions to the group might go as follows.

I. With every issue that comes up for judgment take a majority vote on that issue and, as issues get progressively settled in this way, keep a record of the accumulating body of judgments.

II. If majority voting on some issue generates inconsistency, treat the judgment supported, and any judgments with which it is inconsistent in the record, as candidates for reversal.

III. Identify those candidate judgments-say, the judgments that $\mathrm{p}$, that $\mathrm{q}$, that $\mathrm{r}$, and that not-p\&q\&r-and address the question of how to resolve the inconsistency between them.

IV. If it turns out that some members have independently changed their original opinion on some issue, ask whether this will resolve the inconsistency, and if it does, go with the resulting set of judgments.

$\mathrm{V}$. If the inconsistency is not resolved thereby, take a vote on where it would be best to revise the judgments: whether, for example, to revise the judgment that $\mathrm{p}$, that $\mathrm{q}$, that $\mathrm{r}$, or that not-p\&q\&r.

VI. Take the proposition identified in this way, and hold another vote on how the group should judge that proposition. 
VII. If the group reverses its previous judgment, treat the new verdict on that proposition as the one to be endorsed by the group.

VIII. If the previous judgment is not reversed in that vote, go back to stage III and try again.

IX. If it appears that there is no prospect of success in this process, try to quarantine the inconsistency, and the area of decision it would affect, so that it does not generate problems elsewhere.

$\mathrm{X}$. If this quarantining is not possible, perhaps because the area of action affected is important to the group's aims, there is no alternative but to disband; go your separate ways.

The approach prescribed in these instructions would escape the impossibility theorem because it breaches the systematicity condition in the same way as its static counterparts. So far as the approach is implemented-or at least implemented beyond stage IV-there will be some issues decided on a basis other than that of the majority position of members. If the members of our working group were to follow this procedure, for example, and were to decide that they ought to reverse the majority view on whether to have a pay sacrifice, then the judgment on that issue would not be decided by reference to the majority procedure followed with other issues. The issue about the pay sacrifice would be determined, not in its own right, but on the basis of the views of the group on the other three issues discussed.

This approach, or an approach in the same general family, is the only way I see in which a group might realize the ideal of participatory democracy-the ideal of conducting its business on the basis of a unanimously accepted pattern of majority voting - and yet not fall afoul of the problem illustrated in the discursive dilemma. That is its great merit. The problem with the approach, of course, is that it cannot be relied upon to produce a surefire resolution. It may lead the group to try to live with inconsistency, as in the quarantining option, or it may lead the group to disband. And whether it is to lead in a negative direction of that kind or along a more positive route may turn on nothing more reliable than fortune. The chemistry between members, the resources of rhetoric and persuasion available to them, or just the pressures under which they operate may determine the extent to which the exercise succeeds. The approach falls well short of an algorithm for participatory democracy.

The process may be deficient in other respects too. It may be subject to influence from the order in which issues happen to be taken, it may be vulnerable to insincere voting on the part of more strategic members, it may represent only a fallible way of tracking the truth on the questions addressed. In 
short, it may be hostage to all the usual slings and arrows. But did we have reason to expect anything else? This may still be as good as it gets.

\section{We-thinking}

The most striking way in which the process described falls short of being an algorithmic decision procedure is in the room it makes for deliberation and in the reliance that it is bound to place on deliberation at various points. It makes room for deliberation not only at the point where each thinks about how to judge and vote but also when a range of other issues come up. These are issues to do with whether to revise that original judgment in light of the opinions of others; what the best issue is on which to revise the group judgment; how to vote personally on a proposition that is put up for revision; and whether it may be possible to quarantine any inconsistencies that the group cannot eliminate.

The deliberation accommodated at these loci may be more personal or more communal; it may involve thinking to oneself or also, as in the normal case, exchanging with others. But whatever form it takes, it must induce people to think in terms of "we, the group" rather than "I, this member." I conclude the paper with a discussion of that claim.

Any decision-making group that resolves issues of inconsistency along the participatory line sketched in the last section-or indeed on many of the alternative lines-will constitute itself as a more or less autonomous group agent. My claim about we-thinking is that in order to give life to that agent, the members of the group will have to begin thinking, not just as executors of their own personal attitudes, but also as executors of this distinct entity. They

will have to think in terms of a plural as well as a personal identity (Rovane 1997).

Let it be agreed that a group will constitute an agent or subject that is distinct from its members so far as its intentional states get set up in a way that makes them more or less independent from the intentional states of a majority of members. Were the goals and judgments of the group just whatever goals and judgments happened to be espoused by a majority of the members, then we might well think that talking of the group and its attitudes was just a fancy way of talking about the majority attitudes among its members. That is the sort of position adopted by many thinkers who have wanted to say that the only true agents are individuals; that, in the words of John Austin, 
the nineteenth-century utilitarian, groups can be described as subjects "only by figment, and for the sake of brevity of discussion" (Austin 1869, 364).

In a well-known discussion, Anthony Quinton $(1975,17)$ argues for precisely this point of view. He maintains that to ascribe judgments, intentions, and the like to social groups is just a way of ascribing them, in a summative manner, to individuals in those groups. And he denies, for that reason, that there ever are group agents.

We do, of course, speak freely of the mental properties and acts of a group in the way we do of individual people. Groups are said to have beliefs, emotions, and attitudes and to take decisions and make promises. But these ways of speaking are plainly metaphorical. To ascribe mental predicates to a group is always an indirect way of ascribing such predicates to its members. With such mental states as beliefs and attitudes, the ascriptions are of what I have called a summative kind. To say that the industrial working class is determined to resist anti-trade union laws is to say that all or most industrial workers are so minded.

Our discussion of how a participatory decision-making body might come to form and develop its goals and judgments gives the lie to this "singularist" view that there are no group agents; this view is criticized under that name by Margaret Gilbert $(1989,12)$. For if we consider a group that has followed the dynamic process of judgment formation described, we recognize that on pain of having to live with inconsistency, it will almost inevitably have come to form some judgments that do not correspond to the majority judgments of its members; indeed it may even have come to form judgments that none of its members endorses. Imagine for example that the workers in our example come to accept that they as a group should give up the pay sacrifice. In that case, they will endorse as a group a judgment that they all reject as individuals. They will do so as a result of recognizing that if they are to hold together as a group that does its business in an effective and rational manner, they will have to make that sort of individual accommodation. They will have to be prepared to condone the idea of the group's holding by commitments that are rejected at the personal level: rejected, not just by a minority of the members, but also by a majority among the membership, even perhaps by every single individual.

Let it be granted, then, that the participatory democratic group is more or less bound to develop this sort of autonomy, becoming a subject with distinct attitudes and actions: a group with a mind of its own (Pettit 2003b). The 
thing to notice now is that if the members are to sustain those attitudes and actions, enacting their shared mind, then they must put their individual identities aside, and must begin to think as a group. This is one sort of deliberative thinking that they cannot avoid, whether or not they conduct the deliberation in their own heads or-surely the natural course-in dialogue with others.

In order to emphasize the sort of identification with the group that members must develop, it may be useful to mark the way in which groups may fail or falter on this front. I have discussed the topic elsewhere, under the title of group akrasia: collective weakness of will (Pettit 2003a).

Imagine a noncommercial academic journal with an editorial committee of three members that resolves all the issues it faces by majority vote. Suppose that the committee votes in January for promising subscribers that there will be no price rise within five years. Suppose that it votes in midyear that it will send papers to external reviewers and be bound by their decision as to whether or not to publish any individual piece. And suppose that in December the committee faces the issue as to whether it should be just as prepared to publish technical papers that involve costly typesetting as it is to publish other papers. The earlier votes will argue against its being prepared to do this, since a rise in the number of technical papers submitted and endorsed by reviewers-endorsed, without any eye to overall production costs-might force it to renege on one or other of those commitments. But nonetheless a majority may support the acceptance of technical papers, without any individual being in any way irrational. The members of the committee might vote as follows.

Price freeze?

\begin{tabular}{llll}
\hline A. & Yes & No & Yes \\
B. & No & Yes & Yes \\
C. & Yes & Yes & No \\
\hline
\end{tabular}

The group now faces a hard choice of precisely the kind we have been discussing. Suppose that they implement the participatory democratic process that we characterized in the previous section. And suppose that they agree that the issue on which the group should revise its view is that of whether to treat technical papers on a par with other papers; they may vote unanimously that it is impossible to revise its position on either of the other issues, perhaps because the editorial position on those questions has already been made public. How, then, may we expect the consequent vote to go? 
If members are individually devoted in a consuming, wholehearted way to the group and are in no way tempted to defect from what it requires of them, then of course they will each vote for offering less than equal treatment to technical papers; they will reverse the previous group position. A group whose members were dedicated in this way would operate like a perfectly virtuous agent, always spontaneously supporting what the balance of available reasons requires of the group. But not all members need be so devoted to the group in which they figure; and when something less than full collective devotion is on offer, then it may prove very difficult for members to get their act together and ensure that the group lives up to the considerations that it endorses.

Take the majority who originally supported an open policy on technical papers. That majority may remain individually and stubbornly inclined to support the acceptance of technical papers. We can imagine them turning their eyes from the group as a whole, and sticking to their votes when the issue is raised again. We can imagine them refusing to hear the call of the group and acting like encapsulated centers of voting who are responsive only to their own modular prompts. As we imagine this, we envisage the group failing to reverse its judgment on the only issue where every member of the group thinks it is possible to reverse judgment.

The recalcitrant majority in this sort of case might be moved by a more or less selfish inclination or identification, being technically minded themselves, or they might be moved by a sense of fairness toward those who would be disadvantaged; personal virtue is as likely as personal vice to source recalcitrance towards the collectivity. But could it really be rational for the recalcitrant members to stick to a deviant pattern of voting, whether out of individual bias or virtue? I don't see why not. They would satisfy their private motives, partial or impartial, by doing so. And they might individually expect to get away with such voting, being outvoted by others; they might each expect a free ride. Or they might hope that even if a majority remains recalcitrant, this will not cause problems: there will not be a deluge in the number of technical papers submitted and accepted, and the committee can get away with holding by all of the three commitments involved.

The possibility of people remaining encapsulated in their personal identities in this way, and the danger that that holds out for the survival of the group, shows why it is essential in general that the members should break of out their capsules. If the group is to evolve as a center of agency, with a capacity to be responsive to the demands of consistency, then it must be able to discipline itself into holding only by certain patterns of judgment; it must be able to regulate itself for the formation or maintenance only of judgments 
that cohere with one another. And if a group is to have that capacity, then its members must be able to put their own views aside, identify with the group as an independent center of intentionality, and then reason and act from the perspective of that common center. They must be able to depart from normal, I-centered patterns of thought and begin to think in terms the "we."

This brings our considerations to a close. We have seen that the ideal of participatory democracy, as an ideal for a decision-making body, runs into trouble with the discursive dilemma, and with the more general problem of aggregating individual sets of judgments into a consistent, group-level set of judgments. There is a way of overcoming that problem, as we saw in the last section, that preserves the ideal of participatory democracy. But this, so we have just seen, requires people to deliberate with themselves or one another from the perspective of how we, the members of the group, see the world, not from the perspective that is proper to each in their individual person.

With perhaps a different view in his sights, G. A. Cohen $(1976,66)$ inveighs against the suggestion that one might be reasonably engulfed in a role to the point of holding by certain judgments as an occupant of that role, but not in one's own right. "The propensity to engulfment should be resisted in theory and in practice, for it poses a threat to the exercise of our freedom, and, ultimately, some threat to freedom itself." If the line of argument in this paper is correct, then that is dead wrong. Few will deny the connection, however complex, between the ideal of participatory democracy and the ideal of freedom. And if my argument is right, then the only way to achieve participatory democracy in decision-making forums is precisely to persuade people that they should lend their minds to the service of a group mind; they should learn to think, not just in their own personal name, but in the name of any group in which they democratically participate.

None of this should come as a surprise to those like Carole Pateman who have emphasized the participatory point of view in politics. Participatory democracy requires people to cooperate, not just in the pursuit of common goals, but in the pursuit of common goals according to common judgments. And that sort of enterprise is more or less inevitably going to require members to adopt the group point of view and to be prepared, at least in certain contexts, to prioritize their group identity. Participatory democracy is not just a way in which individuals combine to satisfy their existing goals, according to their existing judgments; it is a way in which they combine to determine the goals and judgments that they will enact together. 


\section{References}

Arrow, K. 1963. Social Choice and Individual Values. New York: John Wiley and Sons.

Austin, J. 1869. Lectures on Jurisprudence, or the Philosophy of Positive Lare. London.

Cohen, G. A. 1976. "Beliefs and Roles." In The Philosophy of Mind, edited by J. Glover, 53-66. Oxford: Oxford University Press.

Coleman, J., and J. Ferejohn. 1986. "Democracy and Social Choice." Ethics 97:6-25.

Gilbert, M. 1989. On Social Facts. Princeton: Princeton University Press.

Harman, G. 1986. Change in View. Cambridge, Mass.: MIT Press.

Hobbes, T. [1651] 1994. Leviathan. Indianapolis: Hackett.

List, C. 2002. "Two Concepts of Agreement." The Good Society 11:72-79.

List, C., and P. Pettit. 2002. "The Aggregation of Sets of Judgments: An Impossibility Result." Economics and Philosophy 18:89-110.

- 2004. "Aggregating Sets of Judgments: Two Impossibility Results Compared." Synthese 140:207-35.

- 2005. "On the Many as One." Philosophy and Public Affairs 33:377-90.

Pateman, C. 1970. Participation and Democratic Theory. Cambridge, Cambridge University Press.

Pettit, P. 2001. A Theory of Freedom: From the Psychology to the Politics of Agency. Cambridge: Polity; and New York: Oxford University Press.

- 2003a. "Akrasia, Collective and Individual." In Weakness of Will and Practical Irrationality, edited by S. Stroud and C. Tappolet, 68-96. Oxford: Oxford University Press.

— 2003b. "Groups with Minds of Their Own." In Socializing Metaphysics, edited by F. Schmitt, 167-93. New York: Rowman and Littlefield.

2006. "Preference, Deliberation, and Satisfaction." In Preferences and Well-being, edited by S. Olsaretti, 131-53. Cambridge: Cambridge University Press.

Quinton, A. 1975. "Social Objects." Proceedings of the Aristotelian Society $76: 1-27$.

Rawls, J. 1971. A Theory of Justice. Oxford: Oxford University Press.

- 1993. Political Liberalism. New York: Columbia University Press.

Rousseau, J.-J. [1750, 1755, 1762] 1973. The Social Contract and Discourses. London: J. M. Dent.

Rovane, C. 1997. The Bounds of Agency: An Essay in Revisionary Metaphysics. Princeton: Princeton University Press. 
Rubenfeld, J. 2001. Freedom and Time: A Theory of Constitutional Self-government. New Haven: Yale University Press.

Sunstein, C. 1993. "Democracy and Shifting Preferences.” In The Idea of Democracy, edited by D. Copp, J. Hampton, and J. E. Roemer, 196-230. Cambridge: Cambridge University Press.

Waldron, J. 1999. Law and Disagreement. Oxford: Oxford University Press. 